\title{
In-Plane Seismic Performance of Plain and TRM-Strengthened Rammed Earth Components
}

\author{
Reza Allahvirdizadeh, Daniel V. Oliveira, Rui A. Silva \\ ISISE, Department of Civil Engineering, University of Minho, Guimarães, Portugal
}

Contacting author: allahvirdizadeh@gmail.com ; danvco@civil.uminho.pt ; ruisilva@civil.uminho.pt

\begin{abstract}
Raw earth is one of the most widely used building materials and is employed in different techniques, among which adobe and rammed earth are the most common. The respective structural systems, like in masonry buildings, acceptably withstand against gravity loads, though they are significantly vulnerable to earthquakes. Moreover, a great percentage of the World's population is still inhabited in such environments, which are endangered by future earthquakes. The current article investigates the seismic in-plane performance of an l-shaped rammed earth component by means of advanced nonlinear finite element modelling. In this regard, conventional pushover analyses were conducted to evaluate load/displacement capacities and to assess probable failure modes. It was observed that the component fails mainly due to detachment of the wing walls from the web wall and due to occurrence of diagonal shear cracks at the web. Subsequently, the application of Textile Reinforced Mortar (TRM) strengthening solution to the component was studied and shown to be able to maintain the integrity of the component for larger lateral load levels. Finally, the reliability of the pushover analyses to predict the seismic response was evaluated by comparison with outcomes from incremental nonlinear dynamic analysis.
\end{abstract}

Keywords: Rammed Earth; TRM; Seismic Behaviour; Pushover Analysis; Dynamic Analysis.

\section{Introduction}

Raw earth is probably the most naturally available building material around the world. Thus, extensive earth architecture is found worldwide (see Figure 1) in the form of a variety of techniques developed through time. Among them, adobe and rammed earth are the most common. Despite nowadays raw earth being rarely used in new constructions from developed countries, a significant percentage of the World's population still inhabits earth buildings, while numerous historical buildings were built using this material.

Considering the aforementioned facts, the need for investigating the different damaging agents affecting these buildings and developing efficient intervention solutions becomes evident. Under service conditions, earth constructions can be damaged by several agents, such as rainwater, soluble salts and temperature oscillations [1]. Regarding the structural performance, it is expected that earthen structures easily withstand gravity loads. However, they can be severely damaged under earthquake excitations due to their low tensile strength, weak connections between structural elements and high inertial forces. Such catastrophic failures have been reported in past earthquakes, namely in Turkey (Erzinkan 1992), Iran (Bam 2003), Peru (Pisco 2007) and Chile (Concepción 2010). Despite this limitation, a significant percentage of these buildings were built in regions with moderate to high seismic hazard (see Figure 1). Thus, the millions of inhabitants continuously exposed to 
seismic risk justify the urgent investigation of the seismic performance of earthen structures and the development of efficient strengthening solutions.

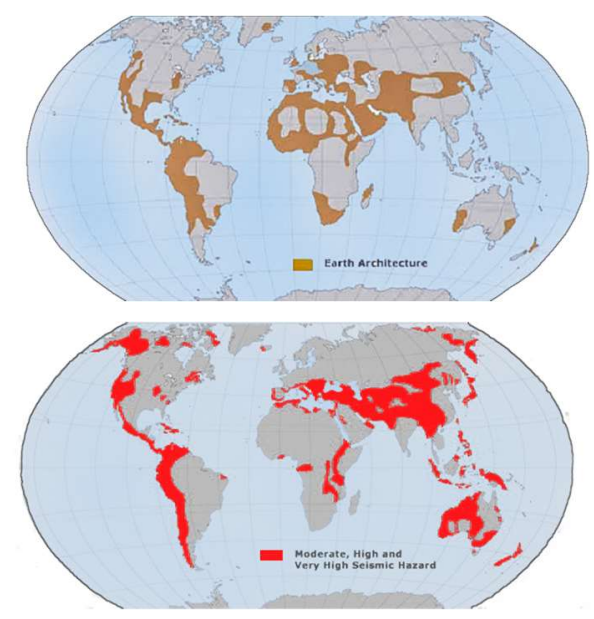

Figure 1. Comparison of geographical distribution of earthen construction and seismic hazard [2]

The current study is focused on the seismic performance of rammed earth walls, particularly on their in-plane response. In this technique, the soil with desired particle size and adequate moisture content is placed between two parallel shutters and then is rammed to obtain a compact layer. The process is repeated until the formwork is filled. The ramming process can be conducted manually (the traditional method) or using pneumatic rammers. Figure 2 illustrates the building process.

Several solutions are proposed in the literature for strengthening of masonry structures, e.g. grout injection, construction of buttresses, introduction of ties, post-tensioning, etc. Among them, composite-based techniques have recently received great attention.

Such popularity is due to their ease of application and high stiffness and strength to weight ratio. Nevertheless, it was observed that using conventional organic epoxy resins may raise durability issues in the case of masonry substrates.

Additionally, FRP composites (as the most popular choice) are generally expensive and are substantially stronger than what is demanded by relatively very weak materials, such as rammed earth. Therefore, Textile Reinforced Mortar (TRM) strengthening is currently being proposed as a solution with higher compatibility. In this technique, compatible materials such as cement-, lime- or earth-based mortars are used as matrix, while the tensile forces are taken by fibre meshes. An example of TRM application is shown in Figure 3.
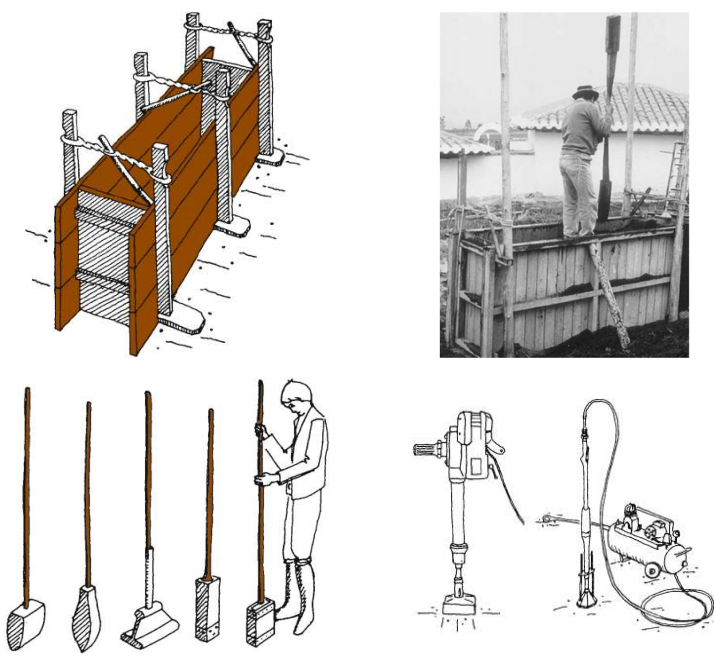

Figure 2. Rammed earth construction technique [3]

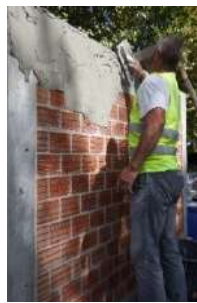

(a) casting thinlayer rendering

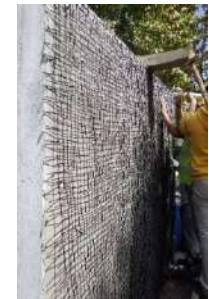

(b) installing meshes

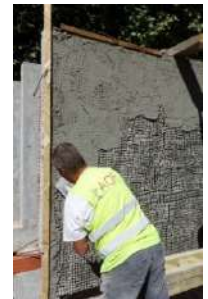

(c) final

rendering
Figure 3. TRM application on a masonry panel [4]

This study presents a numerical investigation that aimed to evaluate the structural behaviour and probable failure modes of rammed earth walls under in-plane lateral loading. The strengthening efficiency of a low cost TRM proposal (hereafter denoted as LC-TRM) implemented on the numerical model was also evaluated. Furthermore, the outcomes of this study serve to support the design of a shaking table test to be conducted in near future.

\section{Model Definition}

The numerical investigation assessed the in-plane response of an idealised wall component by means of pushover and incremental dynamic analyses on a finite element model considering both plain and TRM-strengthened conditions. The definition of the geometry of the model, material behaviours 
adopted and modelling considerations are addressed in the next sections.

\subsection{Wall Geometry}

Rammed earth buildings represent a significant percentage of the built heritage in Alentejo region, southern Portugal. Hence, the outcomes of a survey conducted previously in this region [5] were used to support the definition of the geometry of the numerical model. Eleven buildings were considered from the survey, where the thickness of the walls was in all cases $0.5 \mathrm{~m}$; thus the same value was assumed for the model. Moreover, the average values of the height and length of the walls was found to be about $2.2 \pm 0.3 \mathrm{~m}$ and $3.5 \pm 1.5 \mathrm{~m}$, respectively.

In addition to these representative dimensions, the definition of the geometry of the model should also consider limitations of the testing facilities and the type of behaviour being investigated (in-plane behaviour). The consideration of all conditions resulted in the I-shaped wall component with the dimensions given in Figure 4. It should be noted that the main purpose of the wing walls is to provide lateral stability during the experimental program. Thus, they are required to not change significantly the dominant desired behaviour of the wall. This topic is beyond the scope of this paper, however detailed information regarding the definition of the length of the wing walls can be found in [6].

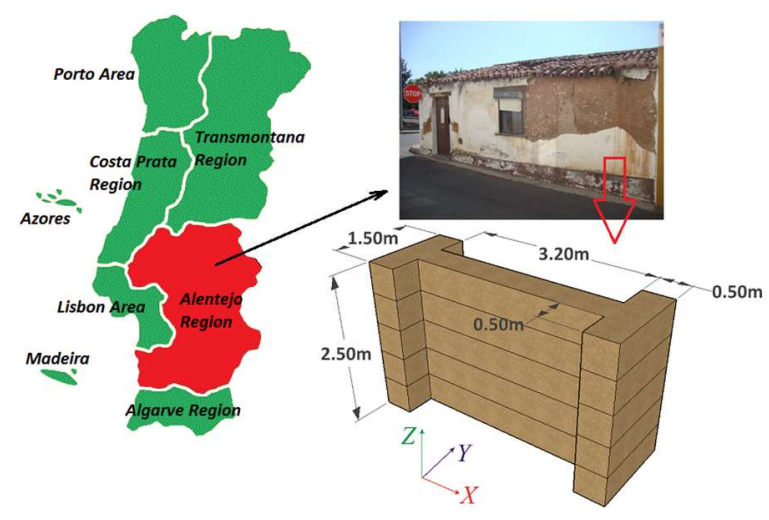

Figure 4. Definition of the geometry of the model

\subsection{Material Properties}

Implementing advanced finite element models to investigate the response of both plain and TRMstrengthened rammed earth walls requires defining adequate nonlinear material constitutive laws and properties of substrate (rammed earth), strengthening (LC-TRM) and of the bond behaviour between all materials (mesh-mortar and mortarrammed earth). Previous experimental results allowed the definition of the constitutive models adopted, nevertheless to the knowledge of authors, no experimental data is currently available on the bond behaviour of TRM-strengthened rammed earth. Hence, the rammed earth and the LC-TRM were assumed as perfectly bonded. Also, the LC-TRM was modelled as a single material, meaning that the model is not capable of simulating mesh sliding within the mortar.

The investigation followed a macro-modelling strategy, meaning that the interface between rammed earth layers is not explicitly modelled. Despite of such simplification, previous numerical studies have shown that neglecting the interface behaviour (macro- vs. micro-modelling) does not impose significant errors with respect to the inplane shear behaviour [7].

Similarly to masonry, unstabilised rammed earth presents very low tensile strength. However, it has been demonstrated that its behaviour can be accurately simulated with smeared cracking models [7], such as the total strain rotating crack model adopted in this investigation. In turn, the behaviour in compression is characterised by low compressive strength and an expressive nonlinear behaviour since very low stress levels. Thus, adopting parabolic relationships in compression, conventionally used for modelling concrete and masonry, has been shown to result in numerical behaviour stiffer than the experimental one. Thus, the use of multi-linear relationships obtained from experimental compression stress-strain curves is recommended instead [7-8]. The same approach was followed in this study and the adopted relationship is presented in Figure 5, which was obtained with basis on experimental results [9]. It should be noted that the experimental post-peak response is not depicted, thus the stress degradation in this phase was idealised to follow linearly the trend of the available experimental data. The tensile behaviour was assumed to follow an exponential relationship with tensile strength of $0.05 \mathrm{MPa}$ and mode-I tensile fracture energy of $0.074 \mathrm{~N} / \mathrm{mm}$. 
The total strain rotating crack model was also used for simulating the behaviour of the LC-TRM behaviour, constituted by an earth-based mortar and a low cost glass fibre mesh. The definition of LC-TRM behaviour considered the composite tensile behaviour in tension (tensile tests of coupons) and the compression behaviour of the mortar in compression. The experimental curves of [10-11] were used to define the adopted multilinear relationships, as portrayed in Figure 6. A detailed discussion regarding the adopted material characteristics can be found in [6,12-13].

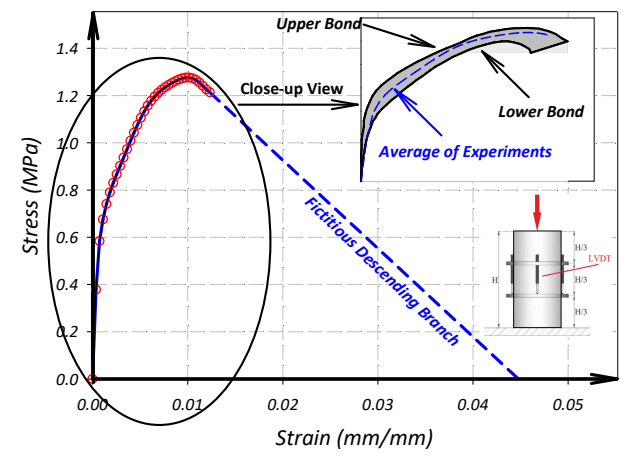

Figure 5. Adopted stress-strain behaviour of the rammed earth in compression

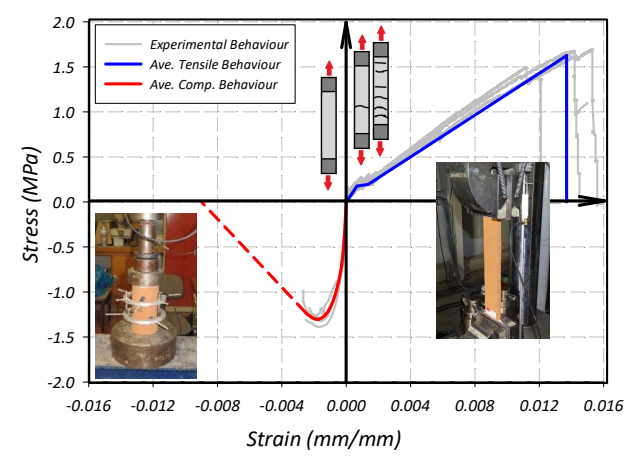

Figure 6. Adopted stress-strain behaviour of the LC-TRM strengthening

\subsection{FE Modelling Considerations}

The finite element software DIANA FEA [14] was used to implement the nonlinear models and conduct the analyses. Previous works have shown that the modelling of rammed earth walls with shell elements results in diverged predictions due to their large thickness in comparison with the other dimensions [6]. Thus, 20 nodes iso-parametric brick elements (see Figure 7a), were adopted for this purpose. Subsequently, the applied LC-TRM strengthening was modelled with 8 node quadrilateral curved shell elements (see Figure 7b). Moreover, the perfectly bonded (rigid) interface between LC-TRM and the rammed earth was modelled using 16 nodes $(8+8)$ plane quadrilateral interface elements (see Figure 7c).

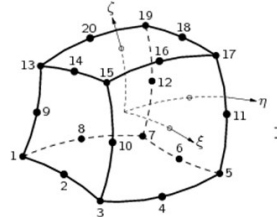

(a) $\mathrm{CHX60}$

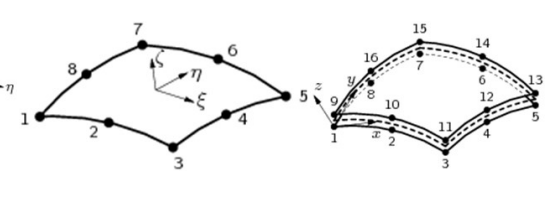

(b) CQ40S (c) $\mathrm{CQ} 48$
Figure 7. Element types used in the models [14]

Before conducting the structural analyses, a mesh sensitivity analysis was performed by considering three mesh sizes, i.e. $25 \mathrm{~mm}, 50 \mathrm{~mm}$ and $100 \mathrm{~mm}$. It was observed that the model with mesh size equal to $100 \mathrm{~mm}$ can accurately predict the response, being this meshing size adopted in the subsequent analyses.

\section{Pushover Analyses}

This section presents the mass proportional pushover analyses conducted to characterize the behaviour of both plain and strengthened models. The resulting pushover curves considered three control nodes on top of the wall, namely left wing $(\mathrm{LW})$, middle web (W) and right wing (RW). It is worthwhile to note that due to the symmetric geometry of the wall, the models were only pushed in the positive in-plane direction $(\mathrm{X})$. The pushover curves of the plain model and the location of the control points are presented in Figure 8.

The right wing controls the behaviour of the wall. Hence, for sake of brevity only the outcomes referring to the RW control point are subsequently presented. As it can be seen from the pushover curve, the wall experiences damage (cracks) at low lateral load levels due to the low tensile strength of the rammed earth. Nevertheless, this damage is local, since the model remains globally linear and achieves about three times higher loading capacity. 


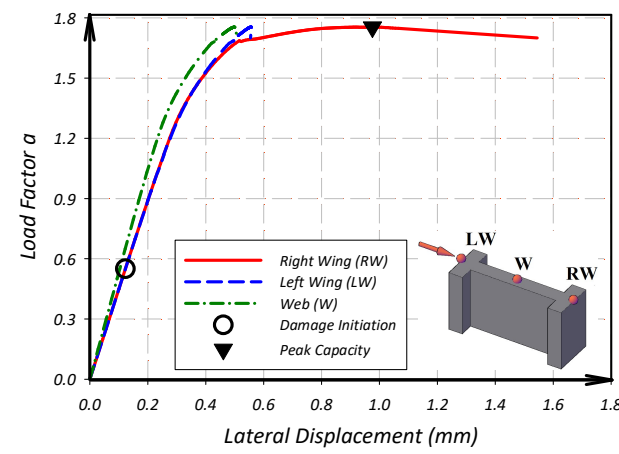

Figure 8. Pushover curve of the plain model

Figure 9 compares the pushover curve of the strengthened model with that of the plain one in order to evaluate the influence of the LC-TRM strengthening on the behaviour of the wall. The strengthening has negligible influence on the elastic stiffness and damage initiation load level. Nevertheless, the loading capacity and its corresponding displacement increased $21 \%$ and $90 \%$, respectively. Thus, the ductility of the model was clearly enhanced, which evidences the efficiency of the LC-TRM in improving the stability and integrity of the model.

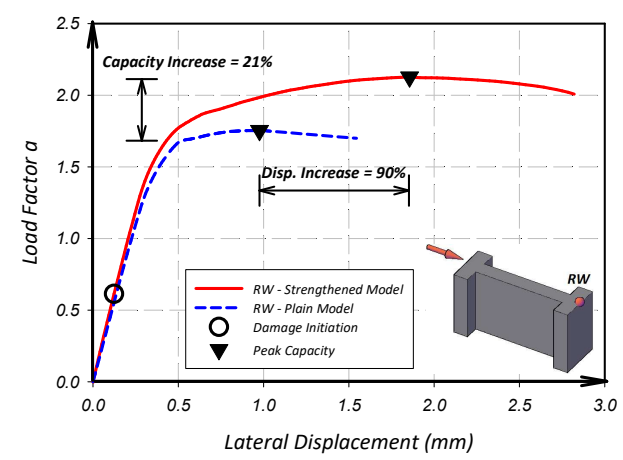

Figure 9. Pushover curve of the strengthened model in comparison to the plain one

The influence of LC-TRM strengthening on the failure mode of the wall was also investigated in terms of principal tensile strains at different load levels. Figure 10 presents the principal tensile strain contours of the plain and strengthened models and of the LC-TRM strengthening itself at the peak capacity of the models.

As it can be seen in Figure 10a, the failure mode of the plain model is characterized by detachment of the right wing, formation of diagonal cracks in the web wall and overturning of the model along the base of the left wing.

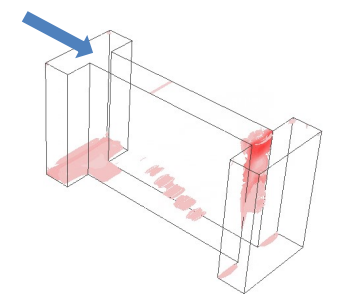

(a) Plain model at its peak

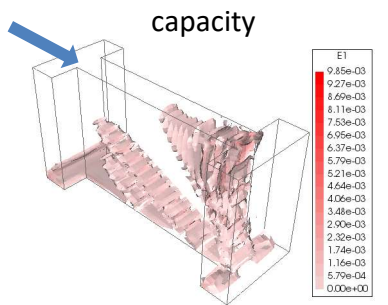

(c) Strengthened model at (d) its peak capacity

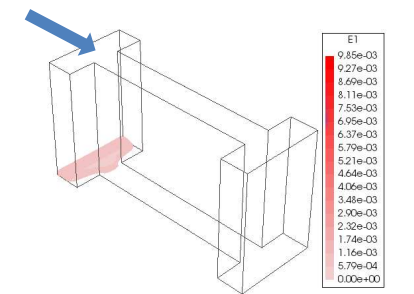

(b) Strengthened model at peak capacity of the plain model

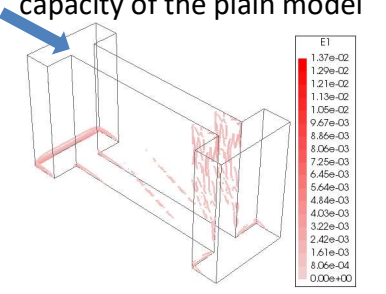

(d) Strengthening at peak capacity of strengthened model
Figure 10. Principal tensile strains of the models

The comparison between the principal tensile strains of the strengthened model at a lateral load level equal to the peak capacity of the plain model (Figure 10b) with that of the plain model reveals that the cracks in the connection between the right wing and the web, and the diagonal cracks at the web of the strengthened model are totally prevented at this stage. Moreover, lower tensile strains at the base of the left wall are observed, which may be interpreted as an improvement of the integrity of the strengthened model.

The principal tensile strains of the strengthened model at its peak capacity (Figure 10c) show that the right wing still tends to detach from the wall, but a considerable portion of the web is prone to sway together. Thus the activation of this failure mode seems to imply an increase of the loading capacity with respect to the plain model. Moreover, the large damage observed in the diagonal crack of the web wall seems to show that a bigger section of it participates in the transference of the lateral loads. This mechanism is favorable for the in-plane behaviour and highlights the efficiency of applying LC-TRM as a strengthening solution for rammed earth walls.

Finally, the principal tensile strains of the strengthening presented in Figure $10 \mathrm{~d}$ allow to evaluate the LC-TRM contribution in the load transferring process of the strengthened model. The strengthening reached its maximum tensile strains at the regions where the rammed earth wall tends to fail. Thus the LC-TRM is able to maintain 
the integrity of the rammed earth component wall in these regions, resulting in the observed improvement of the in-plane performance of the rammed earth.

\section{Nonlinear Time-History Analyses}

Pushover analyses are widely used to assess the seismic performance of structures. Nevertheless, it was previously shown that less reliability is expected from that in comparison to nonlinear time-history analyses. Such divergence in the outcomes between analyses is more evident in simulation of the damage than prediction of the capacity values [15]. Thus, nonlinear dynamic analyses were performed to evaluate reliability/applicability of pushover analyses in assessing the in-plane dynamic behaviour of the rammed earth component.

It should be noted that the responses obtained from nonlinear time-history analyses depend on the applied ground motion. In general, a previously recorded earthquake can be applied by scaling it to be consistent with the seismicity characteristics of the site, or instead, a synthetically generated earthquake can be used. A variety of scaling methods have been proposed in the literature, but their outcomes may significantly differ [16-17]. Investigating the differences resulting from the selection and adopted scaling methods is beyond the scope of the current investigation. Thus, it was decided to adopt an artificially generated ground motion, in the dynamic analyses, as instrumental earthquakes are not available. The ground motion was generated by Simqke_gr software [18] by considering the code spectrum of Odemira municipality in Alentejo region, southern Portugal.

The spectrum of the site for near-field earthquakes [19] is compared with the spectrum of the generated ground motion in Figure 11. Additionally, the three modes of the plain model with highest contribution are depicted. As it can be seen, the model is sensitive to ground motions with high frequency content.

The generated ground motion and its backbone (used in generation process) are presented in Figure 12.

Full dynamic behaviour investigation requires applying a wide range of ground motion intensities, which can be achieved by linearly scaling the considered ground motion records up to the initiation of numerical instability. This method is the so-called Incremental Dynamic Analysis (IDA) and was applied to both plain and strengthened models.

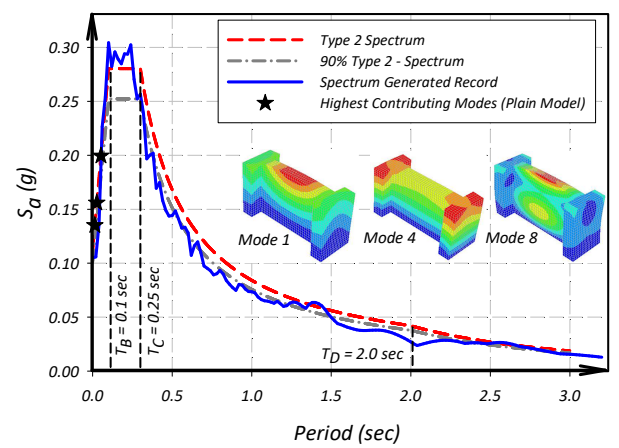

Figure 11. Comparison of the code spectrum with the spectrum of the generated ground motion

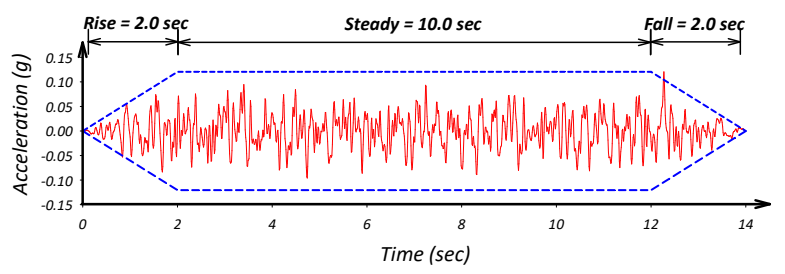

Figure 12. Artificially generated ground motion

As an example of results from the dynamic analyses, Figure 13 presents the experienced lateral displacement of both plain and strengthened models for a scale factor of 4 . In this case, the maximum experienced lateral displacement was significantly decreased (about $40 \%$ ) with the application of LC-TRM strengthening.

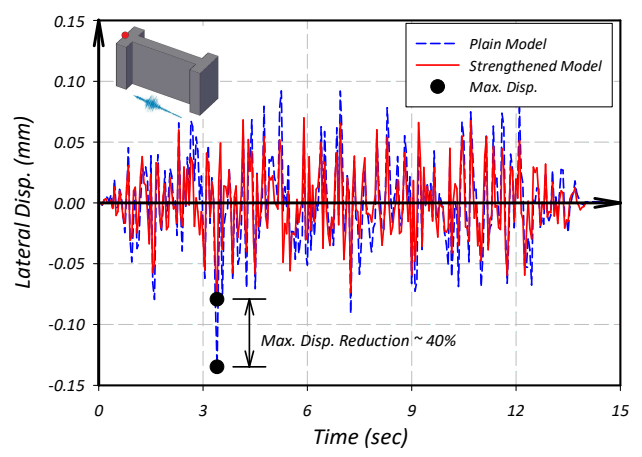

Figure 13. Displacement observed in the plain and strengthened models for a scale factor of 4

In order to compare the outcomes obtained from the nonlinear dynamic analyses with those of the 
pushover analyses, the envelopes of the hysteretic behavior under different earthquake intensities were extracted. An example of these envelope curves for plain model is shown in Figure 14. This intensity corresponds to the initiation of the sway of the controlling wing wall. Each envelope was analyzed to obtain the points with maximum experienced force and displacements, which were used to plot, respectively the force-based and displacement-based IDA responses.

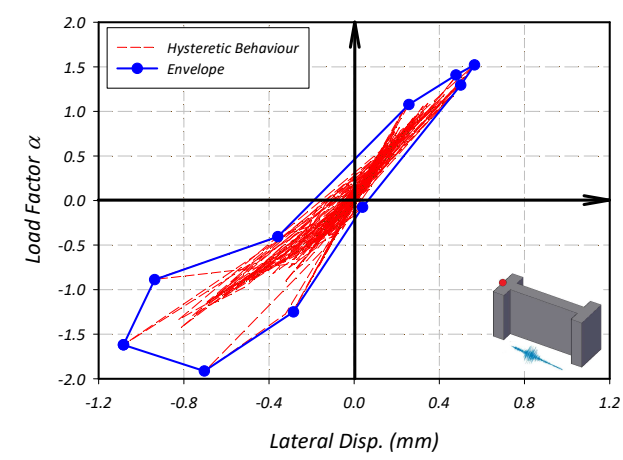

Figure 14. An example of hysteretic curve of the plain model

The previously obtained pushover curves are compared with the force-based and displacementbased IDA responses in Figure 15. The difference between the predicted capacities is very small. In other words, the pushover curve relies between two limits introduced by force-based and displacement-based IDA capacities. Thus, it can be observed that the pushover analyses can reliably predict the in-plane seismic response of the rammed earth model, considering both plain and strengthened situations.

\section{Conclusions}

The in-plane seismic performance of a plain and LCTRM strengthened rammed earth component wall investigated numerically, allowing to draw the following main conclusions.

- Pushover analyses showed that the component probably fails due to detachment of the right wing wall, which is accompanied by the formation of diagonal cracks in the web wall and overturning of the model along the base of the left wing wall.

- The LC-TRM strengthening increased the peak capacity and the corresponding lateral displacement of the model in about $21 \%$ and $90 \%$, respectively.
- The failure of the strengthened model was found to be similar to that of the plain one, nevertheless a larger portion of the web wall tends to detach with the swaying wing, leading to higher capacity. Additionally, larger diagonal crack damage was observed in the strengthened model, evidencing the efficiency of the LC-TRM in activating the desired in-plane behaviour.

- The comparison between the pushover curves and the IDA responses showed that the former can reliably predict the in-plane seismic performance of the plain and strengthened rammed earth component.

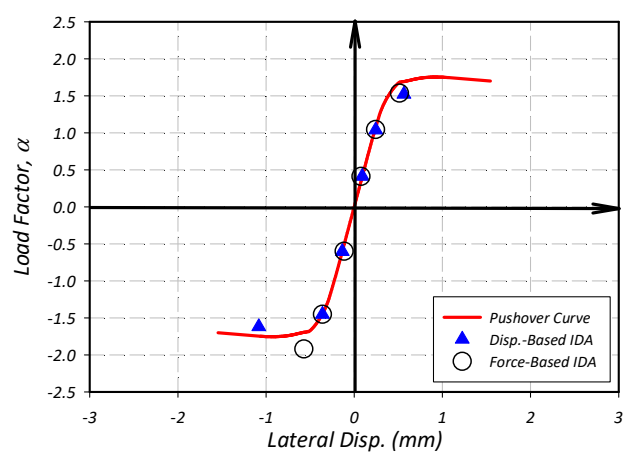

(a) Plain model

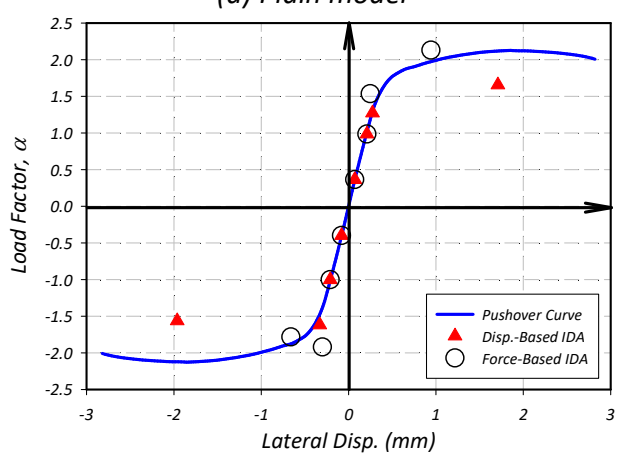

(b) Strengthened model

Figure 15. Comparison between the IDA responses and the pushover curves

\section{Acknowledgments}

This work was financed by FEDER funds through the Competitively Factors Operational Programme COMPETE and by national funds through FCT Foundation for Science and Technology within the scope of projects POCI-01-0145-FEDER-007633 and POCI-01-0145-FEDER-016737 (PTDC/ECM$E S T / 2777 / 2014)$ ). The support from grant SFRH/BPD/97082/2013 is also acknowledged. 


\section{References}

[1] Parreira S.D.J. Seismic Analysis of a Rammed Earth Construction, Master Thesis. Lisbon, Portugal: Instituto Superior Técnico; 2007 [In Portuguese].

[2] De Sensi B. Soil, Dissemination of Earth Architecture. 2003 [in Italian].

[3] Minke G. Building with Earth-Design and Technology of a Sustainable Architecture. Birkhãuser-Publisher for Architecture; 2006.

[4] Akhoundi F., Vasconcelos G., Silva L., Lourenco P., Fanguiero R., and Cunha F. Performance of textile reinforced mortars as strengthening solution of masonry infill walls to seismic action. In: $10^{\circ}$ Congresso Nacional de Sismologia e Engenharia Sismica; 2016 April 20-22; Ponta Delgada, Portugal.

[5] Correia M.R. Rammed Earth in Alentejo. Lisbon: ARGUMENTUM; 2007.

[6] Allahvirdizadeh R. Modelling of the Seismic Behaviour of TRM-Strengthened Rammed Earth Walls, Master Thesis. Guimarães, Portugal: University of Minho; 2017.

[7] Miccoli L., Oliveira D.V., Silva R.A., Müller U., and Schueremans L. Static behaviour of rammed earth: experimental testing and finite element modelling. Materials and Structures. 2015; 61(10): 3443-3456.

[8] Librici C. Modeling of the Seismic Performance of a Rammed Earth Building, Master Thesis. Guimarães, Portugal: University of Minho; 2016.

[9] Silva R.A, Oliveira D.V., Schueremans L., Miranda T., and Machado J. Effectiveness of the Repair of Unstabilised Rammed Earth with Injection of Mud Grouts. Construction and Building Materials. 2016; 127: 861-871.

[10] Barroso C.A. Innovative Seismic Strengthening of Rammed Earth Constructions, Master Thesis. Guimarães, Portugal: University of Minho; 2017 [In Portuguese].

[11] Oliveira D.V., Silva R.A., Barroso C.A, and Lourenco P.B. Characterization of a compatible low cost strengthening solution based on the TRM technique for rammed earth. Key Engineering Materials. 2017; 747: 150-157.

[12] Allahvirdizadeh R., Oliveira D.V., and Silva R.A. Modelling the seismic out-of-plane behaviour of rammed earth components. In: $40^{\text {th }}$ IABSE Symposium; 2018 September 1921; Nantes, France.

[13] Allahvirdizadeh R., Oliveira D.V., and Silva R.A. Numerical modeling of the seismic outof-plane response of a plain and TRMstrengthened rammed earth subassembly. Manuscript submitted for publication.

[14] DIANA FEA BV, Displacement Method ANAlyser, Release 10.1. Netherlands; 2017.

[15] Allahvirdizadeh R., and Gholipour Y. Reliability evaluation of predicted structural performances using nonlinear static analysis. Bulletin of Earthquake Engineering. 2017; 15(5): 2129-2148.

[16] Watson-Lamprey J.A. Selection and scaling of ground motion time-series, Ph.D. Dissertation. Berkeley, USA: University of California; 2007.

[17] Allahvirdizadeh R., Khanmohammadi M., and Marefat M.S. Investigating effects of scaling and selecting earthquake ground motions on performance-based seismic design of $R C$ buildings. $4^{\text {th }}$ International Conference on Concrete \& Development. Tehran, Iran; 2013.

[18] Simqke_gr, Program for generating spectrum-compatible artificial accelerograms. 2012. Available at: http://gelfi.unibs.it/software/simqke/simqk e gr.htm.

[19] IPQ. NP ENV 1998-1: Eurocódigo 8: Projecto de estruturas para Resistência aos sismos Parte 1: Regras gerias, acções sismicas e regras para edificios, Instituto Português da Qualidade, Lisbon; 2009 [In Portuguese]. 